\title{
RECIPROCITY ANALYSIS OF ONLINE LEARNING NETWORKS
}

Reuven Aviv, Ph.D.

Learning International Network Consortium (LINC)

Massachusetts Institute of Technology, Cambridge, U.S. A, and

Department of Computer Science, Open University of Israel

Zippy Erlich

Department of Computer Science, Open University of Israel

Gilad Ravid

Center for Information Technology in Distance Education, Open University of Israel

\begin{abstract}
Asynchronous Learning Networks (ALNs) make the process of collaboration more transparent, because a transcript of conference messages can be used to assess individual roles and contributions and the collaborative process itself. This study considers three aspects of ALNs: the design; the quality of the resulting knowledge construction process; and cohesion, role and power network structures. The design is evaluated according to the Social Interdependence Theory of Cooperative Learning. The quality of the knowledge construction process is evaluated through Content Analysis; and the network structures are analyzed using Social Network Analysis of the response relations among participants during online discussions. In this research we analyze data from two three-month-long ALN academic university courses: a formal, structured, closed forum and an informal, non-structured, open forum. We found that in the structured ALN, the knowledge construction process reached a very high phase of critical thinking and developed cohesive cliques. The students took on bridging and triggering roles, while the tutor had relatively little power. In the non-structured ALN, the knowledge construction process reached a low phase of cognitive activity; few cliques were constructed; most of the students took on the passive role of teacher-followers; and the tutor was at the center of activity. These differences are statistically significant. We conclude that a well-designed ALN develops significant, distinct cohesion, and role and power structures lead the knowledge construction process to high phases of critical thinking.
\end{abstract}

\section{KEYWORDS}

Asynchronous Learning Networks, Learning Effectiveness, Social Network Analysis, Cohesion Analysis, Role Analysis, Power Analysis, Content Analysis

\section{INTRODUCTION}

Asynchronous learning networks (ALN) envision the Internet as primarily a communication facilitator among all parties involved, and secondarily as a medium for distribution of educational materials [1]. Correspondingly, research on online learning relates to educational theory, computers and communication infrastructure, design of educational materials, delivery and quality control [2]. The underlying assumption is that learners are active agents who are purposefully seeking and constructing knowledge within a meaningful context [3-5]. In particular, Dede's theory of distributed learning [6] posits that 
online learners construct knowledge via the reciprocal cognitive growth of members of the learning group. This is a reemphasis of Vygotsky's socio-cultural theory [7] that holds that the results of social interactions are internalized in individuals' cognition. Oshima, Bereiter and Scardamalia [8] confirmed the correlation between cognitive development and knowledge construction. A summarizing review [9] and a comprehensive compendium [2] are available.

Individual members of a distributed learning team form an online learning network (or a virtual community) of joint intelligence which shares the work during the group's learning process. What are the characteristics of such networks? Is an online learning network a social network? Does it maintain various types of communication like a small village community, or is it a single purpose network, like a trigger response gene network [10]? Does it have a distributed or centralized power of influence? Is it cohesive? Some of these questions were studied by analyzing topological features of online learning networks: power of influence [11], correlation of power distributions [12], evolution of cohesion [13], the relations between cohesion and roles and knowledge construction [14], transitivity structures [14, 15] and time variation and media dependence of communication patterns [16].

Interactions, or resource exchanges, are the driving activities of online learning networks [17, 18]. Haythornthwaite, Kazmer, Robins, and Shoemaker [16] noted that the exchanges need not be immediate or one of a kind, but participants do expect to be reciprocated in one way or another. Seabright [19] stated that reciprocity is one of the two distinguishing features of homo sapiens that enable cooperation (the other is the capacity for rational calculation). Similarly, Wellman and Gulia [20] defined reciprocity as one of the defining attributes of any community. Herring's Discourse Analysis [21] includes reciprocity as a behavioral indicator for the emergence of a community. Schwier [22] "unpacked" the metaphor of community into a set of ten elements, one of which is mutuality. Similarly, Chickering and Ehrman [23] incorporated reciprocity as one of the "seven principles for good practice in undergraduate education" and emphasized its importance in the context of problem-based and constructivist paradigms of learning. Common learning environments, such as WebCT [24], increasingly incorporate support for reciprocity. But do we really have reciprocity in online learning networks? Is it theoretically feasible? We examine these questions briefly in the following paragraphs. A more detailed discussion will be presented in section $\mathrm{V}$.

Reciprocity is common in "real life" social networks of people and animals [25], and of organizations [26]. The situation in online networks is less clear. All the reports of which we are aware refer to reciprocity indirectly, with conflicting conclusions. For example, Edwards [27] observed that very little mutual gain of knowledge was achieved in online discussions due to their low perceived value by the participants. Other authors [28] reported that collaborative student learning was unsuccessful, and attributed this to a complex, interacting set of factors, including software and perception issues, and that the online environment was used as a communication tool for organizing work more than a genuine collaborative knowledge-building tool [29]. Other studies [30, 31] reported reciprocal interaction through perspective-taking in online discussions. Swan, Shea, Fredericksen, Pickett, Pelz, and Maher [17, 18] concluded that peer-to-peer interactions were perceived by students as one of the most influential features of online courses. Similarly, Wang [32] found that reciprocation is one of the major motivations driving individual's contributions in online communities.

Network exchange theory [33-37] postulates that actors select their partners. They forge relations with someone who has already related to them or someone who is a promising resource and who will probably reciprocate. To develop reciprocity, learners have to go through a process of assessment of risks, rewards and likelihood of reciprocation. Simulation analysis of the Prisoner's Dilemma game [38] illustrates this idea. When two actors don't trust that their peers will reciprocate, they initially adopt the less risky, lower 
benefit strategy of non-reciprocating; then they may reach a reciprocation state via a series of rounds in which they learn the strategies of their partners [38]. Psychology suggests that during the learning period, each of the actors develops three entities [39]: ego, other, and the reflective-self, which is awareness of ego as the object of one's own investigation as well as the object of investigations by others [40].

It is feasible to establish such a learning period in social networks by using pre-existing, rich "widebandwidth" social links. But relations between actors in online learning communities are not rich. In many cases, students rarely meet, and the existence of the network is limited in scope and in time. The social links have a narrow bandwidth and this, it seems, reduces the likelihood of reciprocation and makes it very difficult to implement a learning period in online networks.

Thus, our starting point in this research is to hypothesize that in contradistinction to social networks, no reciprocity develops in online learning networks (beyond what develops through random interaction). We will test this hypothesis directly on a large set of online networks. The precise formulation of the hypothesis is described in the next section. In section III we describe the database used in this study. The results are presented in section IV, and their meaning is discussed in section $\mathrm{V}$.

\section{HYPOTHESIS FOR RECIPROCITY IN ONLINE LEARNING NETWORKS}

We consider an asynchronous learning network to be one that employs text-based communication. It is a broadcast network in which any posted message is readable by all members ("actors" in this study). The major expectation of actors in such networks is that their messages will be responded to [41, 42], but this does not always happen. Thus, response links might or might not develop: A response link is realized from actor A to actor B if the number of messages posted by B and responded to by A is above threshold, defined in this study as 1 .

Reciprocity arises when pairs of actors have a bidirectional response link; that is, they respond to each other. In this case, the members of the dyad (A, B) elected to respond to each other (at least once). This could occur through random responses to the posters. But it could also be due to some genuine selection process, inherent in the responsiveness relation. Our hypothesis is that actors respond at random; the observed reciprocity is the result of this random process; there is no reciprocal selection process.

To test this hypothesis we need a baseline model for random response. We note that the ability and willingness of an actor to respond are not unlimited. Hence we characterize each actor through two integer-variables, counting the total number of actors with whom that actor could create response links and the number of actors who could create response links with the focus actor. These two variables are the Response Capacities of the actor. The two series of response capacities of all actors in a network are the Response Capacity Sequences of that network. Our baseline model is then defined as follows:

Baseline Model M: Actors randomly select posters to respond to, subject to the constraint that the Response Capacity Sequences of the actors are fixed at some values .

Formally, we will test the following hypothesis:

H0: The observed reciprocity of the response relation in online learning network can be explained by the baseline model, where the response capacity sequences are fixed at the observed values. 


\section{METHOD}

The Open University of Israel is a mixed mode distance learning institute. It combines face-to-face tutorials with intensive use of its learning technologies environment, called Opus. Each course utilizes at least one online discussion forum, usually over one semester. The objectives of the forums vary-from collaborative knowledge construction [14], to social, pedagogical or technical support. There are no participation requirements in any of the forums. Accordingly, size, response links and participation patterns vary from course to course and from semester to semester.

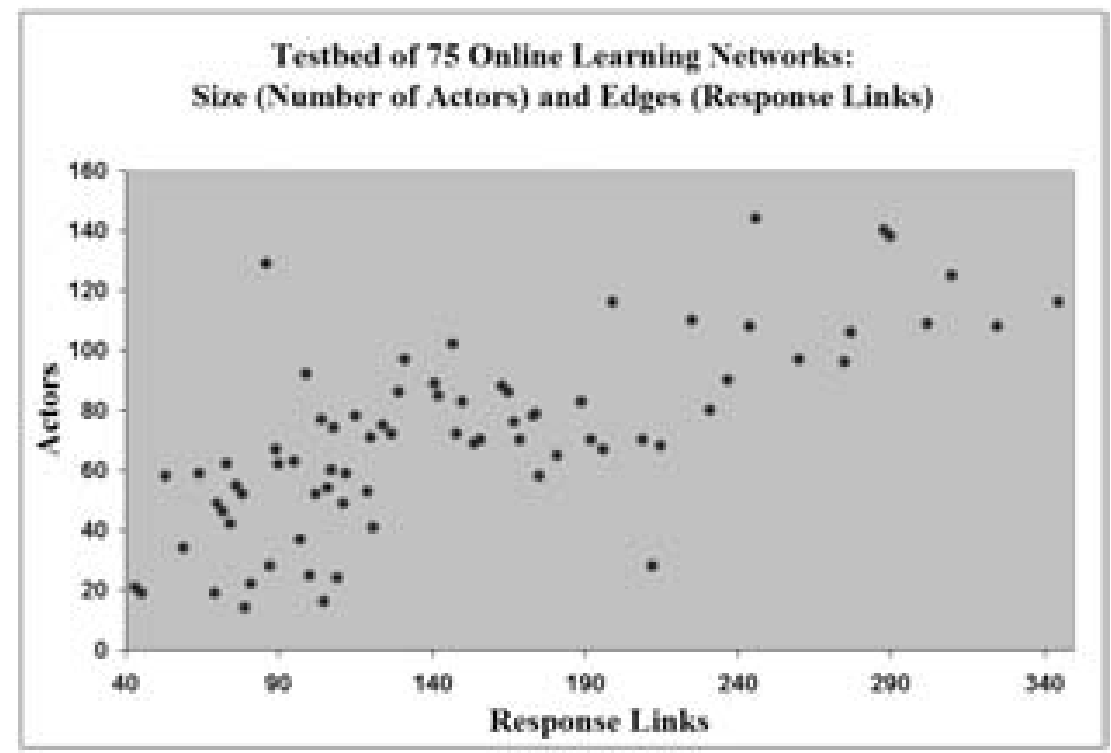

Figure 1. Characteristics of Online Learning Networks Analyzed in this Study

In this study, we selected 75 online discussion forums at random for analysis. The only criterion for selection was that the number of participants (those who post at least one message during the semester) is above an arbitrarily-selected threshold of 10 . Each of these forums is an observed network. As stated above, a response link is defined to exist from actor A to actor B if the number of messages posted by actor B and responded to by actor A was above the threshold defined in this study as 1. Each actor is thus characterized by his or her total response capacity, which is the total number of response links from that actor. Each network is then characterized by its total response capacity, which is the sum of the response capacities of its actors. The distribution of the sizes (number of actors) and the total response capacities of the networks are shown in Figure 1. In the figure, each point represents one network.

We see that the size of the networks ranges from 10 to 160 , and the total response capacity ranges from 40 to 350 . There is no clear relation between these two variables, except that the total response capacity links increase with network size.

We tested hypothesis $\mathrm{H} 0$ for each of the 75 observed networks as follows. For each observed network we created, by simulation [43], an ensemble of 1000 networks that obey the baseline model. For each network in the ensemble we calculated the number of reciprocal dyads. The average of these numbers is the expected number of reciprocal dyads according to the baseline model. We then calculated the fraction of the ensemble networks with reciprocal dyads above and below the observed value. If either of these fractions is smaller than the significance level of 0.01 , the hypothesis is rejected for the particular observed network. Otherwise the hypothesis is accepted. 


\section{RESULTS}

Figure 2 presents the numbers of observed reciprocal dyads and the expected values of such dyads according to the baseline model. It is clear that the observed values are substantially above the expected values. In all the observed networks, the H0 hypothesis is rejected, at $\mathrm{p}<0.01$. The observed reciprocities cannot be explained by the baseline model. Figure 2 also shows "95\% upper bounds" for the number of reciprocal dyads created by the baseline model. Any value above this "bound' has a likelihood of only 5\% or less of appearing in the ensemble of the baseline model. From Figure 2 we see that that all the observed values are above this upper bound.

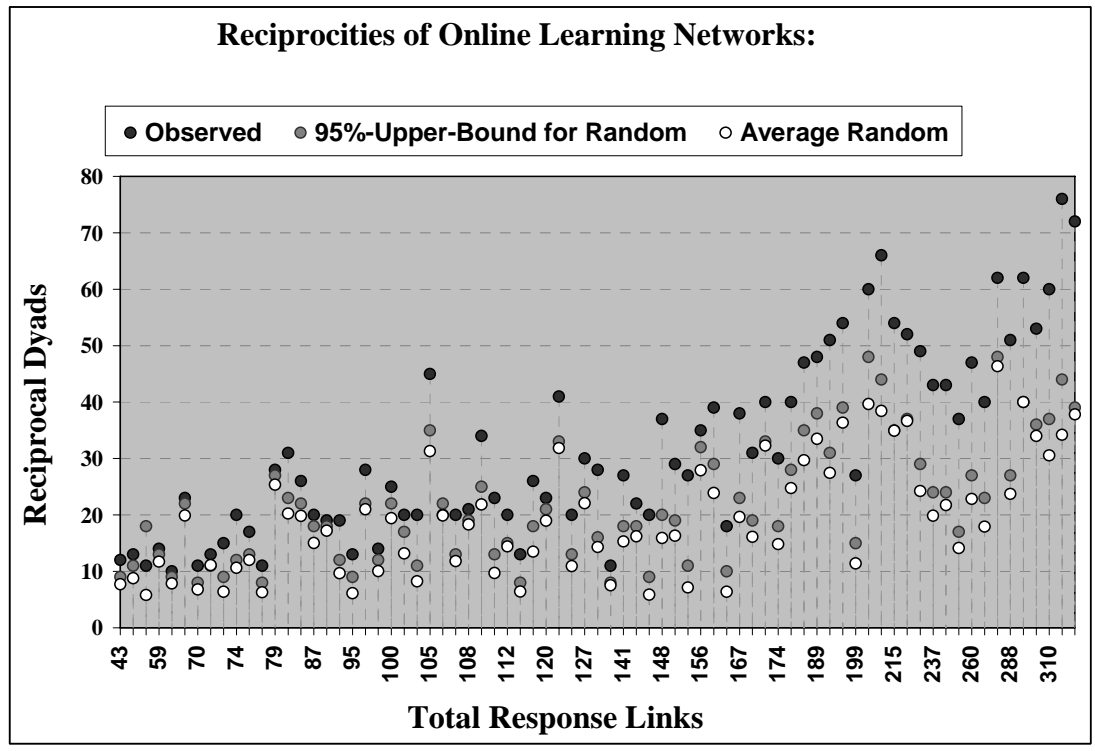

Figure 2. Online Learning Networks: Observed Reciprocal Dyads and Expected M3 Model Values

One may wonder if the observed reciprocities are "real effects," that is, whether they are larger or smaller than values observed in similar-sized social networks. We have calculated a Reciprocity Index [44] for all our online learning networks and for a set of social networks analyzed previously by other scholars [4548]. The Reciprocity Index for a network is the ratio of the reciprocal response capacity to the total response capacity, which is the ratio of the number of reciprocated response links to the total number of response links. Other definitions exist $[49,50]$. The distribution of the reciprocity indices for both sets of networks are presented in Figure 3. 


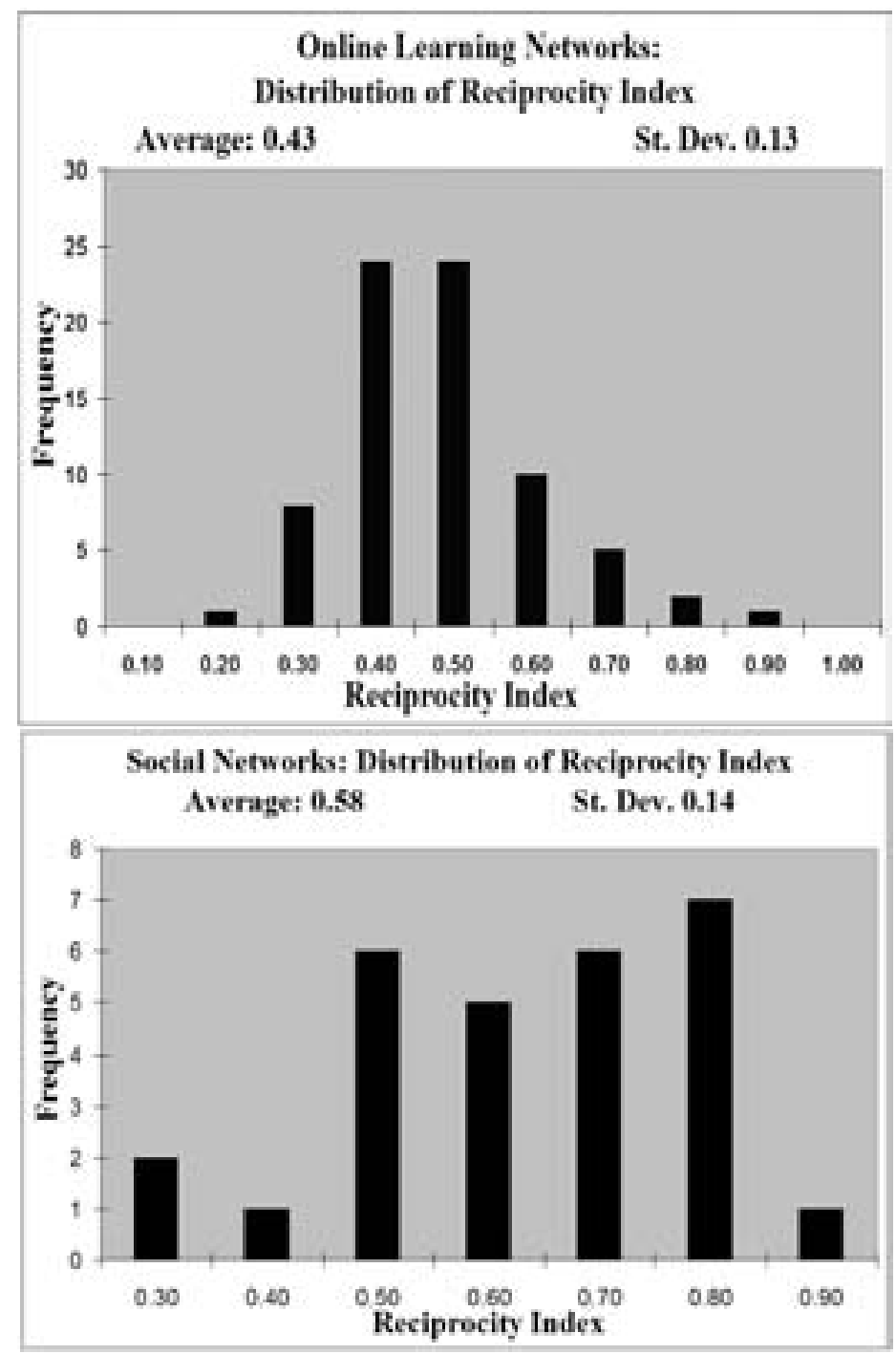

Figure 3. Reciprocity Indices for Online Learning Networks (top) and Social Networks (bottom)

We see that reciprocity indices in the online learning networks are the same size as in social networks, although they seem to be somewhat lower and more homogeneous. In any case, they are not substantially different. Thus, reciprocity is a real effect. The exact shapes of the distributions warrant closer investigation. These and other comparative analyses will be dealt with elsewhere.

\section{DISCUSSION}

Actors in a network obeying the baseline model have freedom to respond to any poster, subject to their fixed individual response capacities. In this model, the selection mechanism of an actor considers its own response capacity as well as the response capacities of the posters before selecting a poster at random to respond to. This mechanism is not sufficient to explain the observed values. This could mean that some reciprocity mechanism is at work. 
Having established the possible existence of a reciprocal exchange mechanism, we now turn to the question of its emergence in online networks. To establish a reciprocal dyad, its actors need to go through a learning period during which they develop the three psychological components of a reciprocal dyad. How can this happen in narrow-band online learning networks? These networks use a broadcast communication mechanism - posted messages are readable by all—so actors learn relatively quickly who is and who is not a potential reciprocator. The learning period is thus shortened. Moreover, actors develop their ego via their postings, which are their "public appearances." They exhibit their own behavioral aspects, such as providers of support or technical advice [51-53], and they attract respect from others. In addition, actors realize that they have to contribute, and possibly to reciprocate, in order to gain anything at all. This leads to the development of the reflective-self component and to the awareness of the other. Finally, interaction and reciprocation are facilitated by the current online communication environment. All these considerations led Wellman and Gulia [20] to conclude that reciprocity is indeed feasible in online communities. Their conclusion is supported by this research.

Reciprocity does not come without a price. The personal view of an actor in a broadcast environment is that the most efficient way to gain social capital is to do nothing. Thus the basic tendency of actors is not to respond at all, let alone reciprocate. Certain design features must be in place to provide responsiveness. The usual procedure is to assign the role of a major responder to one of the actors, usually a tutor. This leads to the most common type of online learning network - the Q\&A forum. Reciprocity in this case implies that students prefer to respond to the tutor than to their peers. Developing a true distributed learning mode is difficult. The remedy is to distribute the roles of responders among a set of actors. Moreover, developing reciprocal dyads comes at the expense of developing more complex structures, such as transitive triads or interconnected cliques, which facilitate constructing knowledge by consensus $[54,55]$. If the goal of the online learning network is indeed knowledge construction, then suitable collaborative features-positive interdependence [56, 57] — should be designed into the network. This fact was demonstrated in a small-scale case study $[58,59]$ and will be expanded in forthcoming research.

\section{CONCLUSION}

This research focused on reciprocity. Reciprocity is only one characteristic of complex networks. There are many others: transitivity, clustering, degree and power distribution, and cliquishness, to name a few. Some of these features affect the behavior of various types of networks. For example, transitivity was found in Social Networks and in gene networks [10,60]. Certain degree distributions (the so called "scale free” distributions [61]) characterize a large number of extremely large networks [62, 63]. These network effects are all interdependent, and can be incorporated into a more general analysis using parametric models, such as $\mathrm{p}^{*}[64,65]$ or biased net models [66]. Such comparative global analyses are required in order to answer the fascinating question: What type of networks are online learning networks?

\section{REFERENCES}

1. Mayadas, A. F. Testimony of A. Frank Mayadas, Program Director, Alfred P. Sloan Foundation. Web-based Education Commission 2000.

2. Anderson, T. and F. Elloumi. Theory and Practice of Online Learning. Athabasca: Athabasca University: 2004. Online: http://cde.athabascau.ca/online_book/.

3. Harasim, L. M. On-line Education: Perspectives on a New Environment. New York, NY: Praeger, 1990.

4. Harasim, L. M. Learning Networks: A Field Guide to Teaching and Learning Online. Cambridge, MA: MIT Press: 1995. 
5. Hiltz, S. R. The Virtual Classroom: Learning Without Limits via Computer Networks. Norwood, NJ: Ablex: 1994.

6. Dede, C. Emerging Technologies and Distributed Learning. American Journal of Distance Education 10: 4-36, 1996. Online: http://www.virtual.gmu.edu/SS_research/cdpapers/ajdepdf.htm.

7. Vygotsky, L. Mind in Society: The Development of Higher Psychological Processes. Cambridge, MA: Harvard University Press: 1978.

8. Oshima, J., C. Bereiter, and M. Scardamalia. Information-Access Characteristics for High Conceptual Progress in a Computer Networked Learning Environment. In Schnase, J. L. and E.L. Cunnius (eds.) Support for Collaborative Learning '95, 259-267. Bloomington, IN: Lawrence Erlbaum Associates, 1995.

9. Hsiao, D. CSCL Theories, 2000. Online: www.edb.utexas.edu/csclstudent/Dhsiao/theories.html.

10. Milo, R., S. Shen-Orr, S. Itzkovitz, N. Kashtan, D. Chklovskii, and U. Alon. Network Motifs: Simple Building Blocks of Complex Networks. Science 298(5594): 824-827, 25 October 2002. Online: http://www.sciencemag.org/cgi/content/abstract/298/5594 /824?ijkey=ab1b429470fac7806f92dcca80a17336e6e402f3\&keytype2=tf_ipsecsha.

11. Martinez, A., Y. Dimitriadis, B. Rubia, E. Gomez, L. Garrachon, and J. A. Marcos. Studying Social Aspects of Computer-Supported Collaboration with a Mixed Evaluation Approach. In Stahl, G. (ed.) Proceedings of Computer Support for Collaborative Learning (CSCL 2002) Conference, 631-632. Mahwah, NJ: Lawrence Erlbaum, 2002.

12. Cho, H., M. Stefanone and G. Gay. Social Network Analysis of Information Sharing Networks in a CSCL Community. In Stahl, G. (ed.) Proceedings of Computer Support for Collaborative Learning (CSCL) 2002 Conference, 43-50. Mahwah, NJ: Lawrence Erlbaum, 2002.

13. Reffay, C. and T. Chanier. Social Network Analysis Used for Modeling Collaboration in Distance Learning Groups. In Cerri, S. A., G. Guarderes, and F. Paraguaco. (eds.) Lecture Notes in Computer Science (LNCS): 31-40, 2002.

14. Aviv, R., Z. Erlich, G. Ravid, and A. Geva. Network Analysis of Knowledge Construction in Asynchronous Learning Networks. Journal of Asynchronous Networks 7: 1-23, 2003. Online: http://www.sloan-c.org/publications/jaln/v7n3/v7n3_aviv.asp.

15. Aviv, R., Erlich, Z. and Ravid, G. Design and Mechanisms of Knowledge Constructing Online Learning Communities The 2nd Annual International MIT LINC Symposium \& Workshop, Cambridge, MA: 2004.

16. Haythornthwaite, C., M. Kazmer, J. Robins, and S. Shoemaker. Community Development Among Distance Learners: Temporal and Technological Dimensions. Journal of Computer Mediated Communication. 6 (1) 2000. Online: http://www.ascusc.org/jcmc/vol6/issue1/haythornthwaite.html.

17. Swan, K. Building Learning Communities in Online Courses: The Importance of Interaction. Education, Communication and Information 2: 23-49, 2002.

18. Swan, K., P. Shea, E. Fredericksen, A. Pickett, W. Pelz, and G. Maher. Building Knowledge Building Communities: Consistency, Contact and Communication in the Virtual Classroom. Journal of Educational Computing Research 23: 389-413, 2000.

19. Seabright, P. The Company of Strangers: A Natural History of Economic Life. Princeton, NJ: Princeton University Press, 2004.

20. Wellman, B. and M. Gulia. Net Surfers Don't Ride Alone: Virtual Communities as Communities. In Kollock, P. and M. Smith. (eds.) Communities and Cyberspace. New York, NY: Routledge, 1999.

21. Herring, S. C. Computer-Mediated Discourse. In Schiffrin, D., D. Tannen, and H. Hamilton. (eds.) The Handbook of Discourse Analysis, 612-634. Oxford: Blackwell, 2001.

22. Schwier, R. A. Shaping the Metaphor of Community in Online Learning Environments 2002. Online: http://cde.athabascau.ca/ISEC2002/papers/schwier.pdf.

23. Chickering, A. and S. Ehrmann. Implementing the Seven Principles: Technology as a Lever. AAHE Bulletin, 49: 3-6, 1996. Online: http://www.tltgroup.org/programs/seven.html.

24. WebCT, WebCT Course Setup and Maintenance, 2003. 
Reciprocity Analysis of Online Learning Networks

25. Skvoretz, J. and K. Faust. Relations, species, and network structure. Journal of Social Structure, 2002. Online: http://www.cmu.edu/joss/content/articles/volume3/SkvoretzFaust.html.

26. Monge, P. R. and N. S. Contractor. Emergence of Communication Networks. In Jablin, F. M. and L.L. Putnam, (eds.) New Handbook of Organizational Communication, 440-502. Newbury Park, CA: Sage, 2001. Online: http://www.tec.spcomm.uiuc.edu/nosh/HOCNets.html.

27. Edwards, C. Discourses on Collaborative Networked Learning Networked Learning Conference, Sheffield, UK 2002. Online: http://www.shef.ac.uk/nlc2002/proceedings/symp/05.htm.

28. Halloran, J., Y. Rogers, and M. Scaife. Taking the 'No' out of Lotus Notes: Activity Theory, Groupware, and Student Groupwork. In Stahl, G. (ed.). Computer Support for Collaborative Learning: Foundations for a CSCL Community, 169-178. Boulder, CO: Lawrence Erlbaum, 2002.

29. Lakkala, M., L. Ilomaki, J. Lallimo, and K. Hakkarainen. Virtual Communication in Middle School Students' and Teachers' Inquiry. In Stahl, G. (ed.) Computer Support for Collaborative Learning: Foundations for a CSCL Community, 443-452. Boulder, CO: Lawrence Erlbaum, 2002: 443-452.

30. Hakkinen, P., S. Jarvela, and A. Byman. Sharing and Making Perspectives in Web-based Conferencing. In Dillenbourg, P., A. Eurelings, and K. Hakkarainen (eds.) Proceedings of the First European Conference on Computer-Supported Collaborative Learning, 285-292. Maastricht: Universiteit Maastricht, 2001.

31. Arnseth, H. C., S. Ludvigsen, B. Wasson, and A. Morch. Collaboration and Problem Solving in Distributed Collaborative Learning Proceedings of EuroCSCL, 75-82. Maastricht, the Netherlands: University of Maastricht, 2001.

32. Wang, Y. and D. R. Fesenmaier. Understanding the Motivation of Contribution in Online Communities: An Empirical Investigation of an Online Travel Community. Electronic Markets 13: 33-45, 2003. Online: http://www.ttra.com/pub/uploads/011.pdf.

33. Homans, G. C. Social Behavior as Exchange. American Journal of Sociology 19: 22-24, 1958.

34. Blau, P. M. Exchange and Power in Social Life. New York, NY: Wiley, 1964.

35. Bienenstock, E. J. and P. Bonacich. Network Exchange as a Cooperative Game. Rationality and Society 9: 37-65, 1997.

36. Markovsky, B., D. Willer, and T. Patton. Power Relations in Exchange Networks. American Sociological Review 53: 220-236, 1998.

37. Willer, D. Network Exchange Theory. Westport, CT: Praeger, 1999.

38. Axelrod, R. The Evolution of Cooperation. New York, NY: Basic Books, 1990.

39. Aron, L. A Meeting of Minds: Mutuality in Psychoanalysis. Hillside, NJ: Analytic Press, 1996.

40. Kadushin, C. Some Basic Network Concepts and Propositions (Draft) 2004. Online: http://stat.gamma.rug.nl/snijders/Kadushin_Concepts.pdf.

41. Rafaeli, S. From New Media to Communication Saage Annual Review of Communication Research: Advancing Communication Science, 110-134. Beverly Hills, CA: Sage, 1988.

42. Rafaeli, S. and R. J. LaRose. Electronic Bulletin Boards and "Public Goods" Explanations of Collaborative Mass Media. Communication Research 20: 277-297, 1993.

43. Snijders, T. A. B. Enumeration and Simulation Methods for 0-1 Matrices with Given Marginals. Psychometrika 56: 397-417, 1991.

44. Zeggelink, E. P. H. Strangers into Friends. The Evolution of Friendship Networks Using an Individual Oriented Modeling Approach. Amsterdam: Thesis Publishers, 1993.

45. Kapferer, B. Strategy and Transaction in an African Factory. Manchester: Manchester Univ. Press, 1972.

46. Knoke, D. and J. Kuklinski. Network Analysis. Beverly Hills, CA: Sage, 1982.

47. Krackhardt, D. Cognitive Social Structures. Social Networks 9: 104-134, 1987.

48. Wasserman, S. and K. Faust. Social Network Analysis: Methods and Applications. Cambridge, UK: Cambridge University Press, 1999.

49. Rao, A. R. and S. Bandyopadhyay. Measures of Reciprocity in a Social Network. Sankhy 49 Ser. A.: 141-148, 1987. 
50. Mandel, M. Measuring Tendency Towards Mutuality in a Social Network. Social Networks 22: 285298, 2000.

51. Hiltz, S. R., K. Johnson, and M. Turoff. Experiments in Group Decision Making: Communication Process and Outcome in Face-to-Face versus Computerized Conferences. Human Communication Research 13: 225-252, 1986.

52. Walther, J. B. Anticipated Ongoing Interaction versus Channel Effects on Relational Communication in Computer-Mediated Interaction. Human Communication Research 20: 473-501, 1994.

53. Constant, D., L. Sproull, and S. Kiesler. The Kindness of Strangers: The Usefulness of Electronic Weak Ties for Technical Advice. Organization Science 7: 119-135, 1996.

54. Aviv, R., Z. Erlich, and G. Ravid. Design and Mechanisms of Knowledge Constructing Online Learning Communities. The 2nd Conference of the Learning International Network Consortium (LINC). Boston: MIT, 2004.

55. Aviv, R., Z. Erlich, and G. Ravid. Mechanisms and Architecture of Online Learning Communities IEEE ICALT, Jonesuu, Finland 2004.

56. Johnson, D. W. and R.T. Johnson. Learning Together and Alone: Cooperative, Competitive and Individualistic Learning. Needham Heights, MA: Allyn and Bacon, 1999.

57. Johnson, D. W. and R. T. Johnson. Positive Interdependence: The Heart of Cooperative Learning. Edina, MN: Interaction, 1992.

58. Aviv, R. Educational Performance of ALN via Content Analysis. Journal of Asynchronous Learning Networks 4: 53-72, 2000.Online: http://www.sloan-c.org/publications/jaln/v4n2/v4n2_aviv.asp.

59. Aviv, R., Z. Erlich, and G. Ravid. Cohesion and Roles: Network Analysis of CSCL Communities IEEE ICALT, Athens, Greece 2003.

60. Shen-Orr, S., R. Milo, S. Mangan, and U. Alon. Network Motifs in the Transcriptional Regulation Network of Escherichia coli. Nature Genetics 31: 64-68, 2000.

61. Barabasi, A. L. and J. Hawoong. Mean-Field Theory for Scale-Free Random Networks. Physica A. 272: 173-187, 1999.

62. Dorogovtsev, S. N. and J. F. F. Mendes. Evolution of Networks: From Biological Nets to the Internet and WWW. Oxford: Oxford University Press, 2004.

63. Newman, M. E. J., A. L. Barabasi, and D. J. Watts. The Structure and Dynamics of Networks. Princeton, NJ: Princeton University Press, 2003.

64. Anderson, C. J., S. Wasserman and B. Crouch. A p* Primer: Logit Model for Social Networks. Social Networks 21: 37-66, 1999.

65. Wasserman, S. and P. Pattison. Logit Models and Logistic Regression for Social Networks. Part I. An Introduction to Markov Graphs and p*. Psychometrika 60: 401-426, 1996.

66. Skvoretz, J. Biased Net Theory: Approximations, Simulations, and Observations. Social Networks 12: 217-238, 1990.

\section{ABOUT THE AUTHORS}

Dr. Reuven Aviv received his M.Sc. in mathematical physics from the Hebrew University, Jerusalem, and a Ph.D. in Mathematical Physics from Tel Aviv University, Israel. Dr. Aviv is a senior lecturer at the Department of Computer Science, and the Chais Research Center, Open University of Israel (OUI) and a visiting scholar at the Learning International Network Consortium (LINC), Massachusetts Institute of Technologies (MIT), Cambridge, USA. He specializes in complex network analysis, communication networks, security and asynchronous learning networks. He was the director of the Tele-Learning Methodologies (TELEM) project and senior consultant to the Director of the Center for Information Technology in Distance Education, both at the OUI. Dr. Aviv has served on the faculty of several universities in Israel, Australia, New Zealand, Thailand and the USA. He has published in the area of network analysis of online communities, learning groups and CSCL. 
Zippy Erlich received her B.Sc. in mathematics and statistics and M.Sc. in mathematics, both from Tel Aviv University, and a Ph.D. in Computer Science from the University of California, Los Angeles. Dr. Erlich is on the faculty of the Department of Computer Science at the Open University of Israel and served as the head of the department for four years. She has developed curricula for undergraduate and graduate programs of study in computer science and headed development teams for a variety of B.Sc. and M.Sc. courses. Before joining the Open University, she headed the data processing department of the Israeli Navy Computer Center. Her research focuses on information systems success measurement, data mining, computer literacy and applications via e-learning, distance learning, and learning networks.

Gilad Ravid received his B.Sc. in Agricultural Engineering from the Technion - Israel Institute of Technology, and his MBA specializing in Management Information Systems and Operations Research, from the Hebrew University of Jerusalem. Mr. Ravid has just completed his doctoral thesis at the University of Haifa, and is the manager of the technical group at the Center for Information Technology and Distance Education at the Open University of Israel. He is a lecturer at the Hebrew University of Jerusalem and the Ruppin Institute. He has published in the areas of distance education, supply chain management simulations, and group online communication.

\section{ACKNOWLEDGEMENTS}

The authors of this paper thank Gila Haimovic for her critical review of the manuscript. 